\title{
In Vitro Assessment of Intracanal Calcium Hydroxide Removal Using Various Irrigation Systems: An SEM Study
}

\author{
Abhinav K Singh ${ }^{1}$, Pavithra K Ramanna ${ }^{2}$, Deesha Kumari ${ }^{3}$, Piyali Poddar ${ }^{4}$, Maitri Shah ${ }^{5}$, Arti Dixit ${ }^{6}$
}

\begin{abstract}
Aim: The aim of this research was to assess the effectiveness of three different irrigation systems in elimination of calcium hydroxide $\left[\mathrm{Ca}(\mathrm{OH})_{2}\right]$ from root canals.

Materials and methods: This in vitro research included ninety recently extracted mandibular premolar teeth with a solitary root. The sample teeth were subjected to disinfection employing sodium hypochlorite at 5.25\%. The root canal preparation was performed followed by placement of premixed $\mathrm{Ca}(\mathrm{OH})_{2}$ within every canal. The sample teeth were then randomly allocated into one of the three experimental groups (each comprising 30 samples) as follows: Group 1, NaviTip FX irrigation system; group 2, Vibringe sonic irrigation system; and group 3, EndoVac apical negative pressure irrigation system. Following the preparation, each of the sample teeth was examined beneath a scanning electron microscope (SEM) at a magnification of $1000 \times$.

Results: An intragroup comparative analysis revealed that the highest $\mathrm{Ca}(\mathrm{OH})_{2}$ elimination was seen at middle third $(0.82 \pm 0.09,0.30 \pm 0.11)$ in NaviTip FX irrigation system and Vibringe sonic irrigation system, respectively. Higher $\mathrm{Ca}(\mathrm{OH})_{2}$ was eliminated at the apical third $(0.26 \pm 0.02)$ by the EndoVac irrigation system. At coronal third, maximum $\mathrm{Ca}(\mathrm{OH})_{2}$ removal was seen in EndoVac irrigation system $(0.49 \pm 0.03)$. A statistically significant difference was noted amid Vibringe sonic irrigation and EndoVac irrigation systems. The intergroup evaluation of $\mathrm{Ca}(\mathrm{OH})_{2}$ elimination at coronal, middle, and apical third showed a statistically significant difference between NaviTip FX irrigation and Vibringe sonic irrigation as well as between NaviTip FX irrigation and EndoVac irrigation at a $p$ value of 0.001 . The difference between EndoVac irrigation and Vibringe sonic irrigation was not statistically significant.
\end{abstract}

Conclusion: Amid the limitations of this research, this research concludes that none among the irrigation methods employed could totally eliminate the $\mathrm{Ca}(\mathrm{OH})_{2}$ off the root canals. Nevertheless, EndoVac apical negative pressure irrigation has slightly superior potential in eliminating $\mathrm{Ca}(\mathrm{OH})_{2}$ from the root canals in comparison with Vibringe sonic irrigation as well as the NaviTip FX irrigation system.

Clinical significance: Even though the $\mathrm{Ca}(\mathrm{OH})_{2}$ is largely suggested as medicament, its elimination at the point of canal obturation is likewise significant and complex as any remaining portion may avoid sealer diffusion inside the dentinal tubules, consequently substantially escalating the apical leakage of endodontically treated teeth.

Keywords: Calcium hydroxide, Irrigation systems, Root canal, Scanning electron microscope.

The Journal of Contemporary Dental Practice (2021): 10.5005/jp-journals-10024-3142

\section{INTRODUCTION}

The triumph of an endodontic treatment depends on a precise diagnosis and planning a suitable therapeutic plan. Unfortunately, the abolition of microorganisms coupled with total elimination of tiny organic debris remnants, necrosed tissue, remaining pulp tissue, and dentin chips from the root canals is amid the ignored phases of root canal treatment. ${ }^{1}$

Herman in the year 1920, pioneered calcium hydroxide $\left[\mathrm{Ca}(\mathrm{OH})_{2}\right]$ that has a very alkaline $\mathrm{pH}$ along with the ability to breakdown to release calcium and hydroxyl ions that exhibit antibacterial action. $\mathrm{Ca}(\mathrm{OH})_{2}$ paste is often used in the field of endodontics as an medication within the root canal owing to its antimicrobial effectiveness against a vast number of root canal pathogenic organisms as well as its biocompatibility. ${ }^{2}$

Prior to endodontic obturation, the $\mathrm{Ca}(\mathrm{OH})_{2}$ medicament that had been coated on to the root canals must be taken off. The presence of $\mathrm{Ca}(\mathrm{OH})_{2}$ remainders on the walls of the root canal has detrimental consequences on the quality of the obturation. In vitro research has noted that $\mathrm{Ca}(\mathrm{OH})_{2}$ residues can deter sealant penetration into tubular dentin and hamper the bond between resin sealer and dentin surface. Additionally, significant apical leakage of endodontically treated teeth and interaction with zinc oxide eugenol sealers that make them granular and fragile have also been noted in the presence of
${ }^{1}$ Department of Conservative Dentistry and Endodontics, Buddha Institute of Dental Sciences and Hospital, Patna, Bihar, India

${ }^{2}$ Department of Prosthodontics, Crown and Bridge and Implantology, Vydehi Institute of Dental Sciences and Research Hospital, Bengaluru, Karnataka, India

${ }^{3}$ Department of Public Health Dentistry, AB Shetty Memorial Institute of Dental Sciences (ABSMIDS), NITTE (Deemed to be University), Mangaluru, Karnataka, India

${ }^{4}$ Department of Public Health Dentistry, Kusum Devi Sunderlal Dugar Jain Dental College and Hospital, Kolkata, West Bengal, India

${ }^{5}$ Department of Conservative Dentistry and Endodontics, Faculty of Dental Science, DDU, Nadiad, Gujarat, India

${ }^{6}$ Department of Public Health Dentistry, Vaidik Dental College and Research Centre, Daman, Daman and Diu, India

Corresponding Author: Abhinav K Singh, Department of Conservative Dentistry and Endodontics, Buddha Institute of Dental Sciences and Hospital, Patna, Bihar, India, Phone: +919576969374, e-mail: akspat01 @gmail.com

How to cite this article: Singh AK, Ramanna PK, Kumari D, et al. In Vitro Assessment of Intracanal Calcium Hydroxide Removal Using Various Irrigation Systems: An SEM Study. J Contemp Dent Pract 2021;22(9):1003-1007.

Source of support: Nil

Conflict of interest: None

(c) The Author(s). 2021 Open Access This article is distributed under the terms of the Creative Commons Attribution 4.0 International License (https://creativecommons. org/licenses/by-nc/4.0/), which permits unrestricted use, distribution, and non-commercial reproduction in any medium, provided you give appropriate credit to the original author(s) and the source, provide a link to the Creative Commons license, and indicate if changes were made. The Creative Commons Public Domain Dedication waiver (http://creativecommons.org/publicdomain/zero/1.0/) applies to the data made available in this article, unless otherwise stated. 
remnants of $\mathrm{Ca}(\mathrm{OH})_{2}$. This thus mandates the total elimination of any $\mathrm{Ca}(\mathrm{OH})_{2}$ residues from the root canal prior to root canal filling. Removal of the $\mathrm{Ca}(\mathrm{OH})_{2}$ remainders in irregular canals can nevertheless be challenging. ${ }^{3}$

Various techniques have been previously recommended to eliminate $\mathrm{Ca}(\mathrm{OH})_{2}$ off the canal walls, including the use of hand and rotary files, passive ultrasonic irrigation, sonic activation, and the canal brush. Clinical practice employs use of hand instruments frequently, utilizing a master apical file under abundant irrigation by sodium hypochlorite. ${ }^{4}$

A NaviTip FX brush covered needle introduced for the irrigation during canal preparation. It eliminates the root canal wall debris chemically and mechanically simultaneously during irrigation. ${ }^{5}$ Vibringe is a sonic washing system, a system in which sonic activation and manual are combined. Along with that, the needle attached to the syringe, the irrigation solution can also be activated sonically. The EndoVac system acts as a apical negative pressure irrigation system, which is designed to deliver irrigation solutions to the apical end portion of the root canal systems and to suction out debris from the root canals. ${ }^{6}$ This research was thus performed to evaluate the effectiveness of different irrigation systems thatpossess differing techniques to eliminate $\mathrm{Ca}(\mathrm{OH})_{2}$ from root canals.

\section{Materials and Methods}

The present study was performed in the Department of Conservative Dentistry and Endodontics, Buddha Institute of Dental Sciences and Hospital, Patna. This in vitro research included ninety recently extracted mandibular premolar teeth with a solitary root, which were removed for periodontal or orthodontic treatment procedures. After the extraction, these sample premolars were subjected to a complete washing beneath running water followed by cleaning by ultrasonic equipment. The sample teeth were then subjected to disinfection employing sodium hypochlorite at $5.25 \%$. Those teeth thathad a solitary root canal, no evidence of radicular dental caries, fractures/cracks, lack of internal/external resorption or calcification, and a fully formed apex were included in the study. The radicular canal morphology was confirmed with pretreatment mesiodistal as well as buccolingual radiographs.

\section{Root Canal Preparation}

A diamond disk (KG Sorensen, Barueri, Sao Paulo, Brazil) under water coolant at a slow speed was used to remove the crowns at the cementoenamel junction to procure a standard radicular length of $10 \mathrm{~mm}$. A K-file of size 10 was then introduced into the canal till it could be seen at the apical foramen. One millimeter subtracted from the aforementioned measurement helped determine the working length. The ProTaper rotary arrangement (Dentsply Maillefer, Ballaigues, Switzerland) was used to instrument the root canals up to a size 30 with $9 \%$ taper (size F3) serving as the master apical file. The root canal was subjected to irrigation with $2 \mathrm{~mL}$ of $2.5 \%$ sodium hypochlorite solution following every instrument throughout the preparation. Irrigation was done using a 27-gauge root canal irrigation syringe that was placed in the canal up to the working length. A final burst was then applied after completion of the instrumentation employing $5 \mathrm{~mL}$ of $17 \%$ ethylenediaminetetraacetic acid (EDTA) and $5 \mathrm{~mL}$ of $2.5 \%$ sodium hypochlorite.

Subsequently, the root canals were subjected to drying using paper points. After this, a premixed $\mathrm{Ca}(\mathrm{OH})_{2}$ (Calcicur, Voco,
Cuxhaven, Germany) was introduced in the canal with a lentulo spiral adjusted till the working length until the medication was evident at the apical foramen. Following this, the cavities thus created by access opening were closed with a small cotton ball and temporary restoration (Cavit, ESPE, Seefeld, Germany). For the next 7 days, these samples were stored at a temperature of $37^{\circ} \mathrm{C}$ as well as $100 \%$ humidity.

Three different systems were then employed to eliminate $\mathrm{Ca}(\mathrm{OH})_{2}$ present in the root canals. These sample teeth were then randomly allocated to one of the three study groups (30 each) as follows:

\section{Group 1: NaviTip FX Irrigation System}

A 30-gauge NaviTip FX tip (Ultradent Products Inc, South Jordan, Utah, United States) was employed for irrigating the canals, which was fit into the body of a disposable syringe of $2.5 \mathrm{~mL}$ volume. Robust irrigation of the root canal systems was performed via the needle utilizing $2.5 \mathrm{~mL}$ of $2.5 \%$ sodium hypochlorite as well as $2.5 \mathrm{~mL}$ of $17 \%$ EDTA for 60 seconds with up and forth motion of the needle.

\section{Group 2: Vibringe Sonic Irrigation System}

A 27-gauge close-end and side vented irrigating needle (Kerr Hawe SA, Bioggio, Switzerland) coupled with Vibringe sonic irrigating apparatus was employed to eliminate $\mathrm{Ca}(\mathrm{OH})_{2}$ from the surface of the root canals. In accordance with the manufacturer's recommendations, the needle was inserted about an $\mathrm{mm}$ or 2 short of the working length. Active irrigation of the radicular canals with help of the needle was done utilizing $2.5 \mathrm{~mL}$ of $2.5 \%$ sodium hypochlorite as well as $2.5 \mathrm{~mL}$ of $17 \%$ EDTA for 60 seconds with up and forth motion of the needle. Following each active irrigating step, the canal was left untouched for a minute to attain passive irrigation. The finishing irrigating step was performed employing $2.5 \mathrm{~mL}$ of $2.5 \%$ sodium hypochlorite for 60 seconds and then again leaving the canal untouched for a minute.

\section{Group 3: EndoVac Apical Negative Pressure Irrigation System}

In this group, the system employed for irrigation was the apical negative pressure irrigation (EndoVac, Discus Dental, Culver City, California, United States). A macrocannula tip was used to carry the irrigant an $\mathrm{mm}$ down the canal after which three phases of microcannula irrigation wereperformed. At every microcannula irrigation phase, the tip was introduced for 6 seconds to the entire working length and then removed by about $2 \mathrm{~mm}$ off the entire working length for around 6 seconds. These steps were repeated across a period spanning 30 seconds. A total of $10 \mathrm{~mL}$ of $2.5 \%$ sodium hypochlorite was used.

\section{Evaluation of Samples under Scanning Electron Microscope}

Following the preparation of the canal as mentioned above, all the sample premolars were subjected to sectioning in the buccolingual direction employing a carborundum disk, prior to which a groove was made buccolingually using a diamond bur. Subsequent to this, each tooth was examined beneath a scanning electron microscope (SEM) (LEO 440i, Carl Zeiss, Tokyo, Japan) at 1000× magnification. Prior to the examination, dehydration of the specimens followed by fixation on stubs of aluminum and sputter coating with gold was accomplished. A four-grade system was used to score the remnants 
of $\mathrm{Ca}(\mathrm{OH})_{2}$ in each sample along with three portions of the radicular canal (coronal, middle, as well as apical): ${ }^{7}$

Score $0=$ Absence of $\mathrm{Ca}(\mathrm{OH})_{2}$ on the root canal surface. Score $1=$ One-third of the root canal surface is covered by $\mathrm{Ca}(\mathrm{OH})_{2}$. Score $2=$ Two-thirds of the root canal surface is covered by $\mathrm{Ca}(\mathrm{OH})_{2}$. Score $3=\mathrm{Ca}(\mathrm{OH})_{2}$ has completely covered the root canal surface.

As a means to avoid bias, two independent skilled observers verified the scores. The mean thus derived from the two observers' scores was statistically analyzed.

\section{Statistical Analysis}

Kruskal-Wallis tests and Mann-Whitney U-test were used to perform the statistical analysis via Statistical Packages for Social Sciences (SPSS) software, version 20.0 for Windows (SPSS Inc., Chicago, Illinois, United States). Statistical significance was set at $p$ value less than 0.05 .

\section{Results}

Table 1 depicts the assessment of mean $\mathrm{Ca}(\mathrm{OH})_{2}$ elimination of the three different irrigation systems at the coronal, middle, and apical third of the root canal surface. An intragroup comparative analysis revealed that the highest $\mathrm{Ca}(\mathrm{OH})_{2}$ elimination was seen at middle third $(0.82 \pm 0.09,0.30 \pm 0.11)$ in NaviTip FX irrigation system and Vibringe sonic irrigation system, respectively. Higher $\mathrm{Ca}(\mathrm{OH})_{2}$ was eliminated at the apical third $(0.26 \pm 0.02)$ by the EndoVac irrigation system. And at coronal third, the maximum $\mathrm{Ca}(\mathrm{OH})_{2}$ removal was seen in EndoVac irrigation system $(0.49 \pm 0.03)$ followed by Vibringe sonic irrigation system $(0.52 \pm 0.07)$ and NaviTip FX irrigation system $(0.89 \pm 0.13)$. A statistically significant difference was noted between Vibringe sonic irrigation and EndoVac irrigation.

Mann-Whitney $U$-test was employed to estimate the intergroup evaluation of $\mathrm{Ca}(\mathrm{OH})_{2}$ elimination at coronal, middle, and apical third. A statistically significant difference was noted between NaviTip FX irrigation and Vibringe sonic irrigation as well as between NaviTip FX irrigation and EndoVac irrigationat a $p$ value of 0.001 . The difference between EndoVac irrigation and Vibringe sonic irrigation was not statistically significant (Tables 2 to 4).

This research thus implies that EndoVac irrigation systems exhibit probableen couraging results in their capability to eliminate
$\mathrm{Ca}(\mathrm{OH})_{2}$ from the root canals at the apical third meticulously pursued by the Vibringe sonic irrigation and NaviTip FX irrigation system in that order.

\section{Discussion}

$\mathrm{Ca}(\mathrm{OH})_{2}$ paste has an extremely alkaline $\mathrm{pH}$ and is an inorganic intracanal medicament. It is highly popular because of its antibacterial effectiveness as well as compatible biologic characteristics. Nevertheless, inability to completely eliminate $\mathrm{Ca}(\mathrm{OH})_{2}$ from the root canals causes buildup of its residues on the walls of the canals that can lead to enhanced canal permeability. This can further impede the sealing efficiency of root canal sealers, finally resulting in endodontic treatment failure. It has additionally been documented that residual $\mathrm{Ca}(\mathrm{OH})_{2}$ within the canals may chemically interact with ZOE sealers with resultant formation of weak calcium eugenolate avoiding sealer penetrability, finally leading to improper bonding of resin sealer to the dentinal surface. ${ }^{8}$ Therefore, every interappointment medication placed within the canal must be meticulously eliminated prior to obturation.

Various techniques to determine the quantity of residual $\mathrm{Ca}(\mathrm{OH})_{2}$ in the root canal walls have been used like stereomicroscope, computed tomography (CT), digital photographs, SEM, micro and spiral CT. ${ }^{9}$ For the purpose of this research, SEM assessment was done with the sample teeth being examined under $1000 \times$ magnification employing a scoring system. Lambrianidis et al. ${ }^{4}$ and Kuga et al. ${ }^{10}$ have employed a comparable method previously, inferring that the scoring structure is rather dependable in comparison with area calculation techniques owing to the challenges in differentiating $\mathrm{Ca}(\mathrm{OH})_{2}$ in certain portions of the dentinal walls because of color likeness.

Irrigation with sodium hypochlorite in the absence of activation has been documented to be insufficient for the elimination of $\mathrm{Ca}(\mathrm{OH})_{2}$ from radicular canals due to restricted capability to liquefy inorganic substances. ${ }^{11}$ Margelos et al. ${ }^{12}$ have shown that the use of $15 \%$ EDTA solution or sodium hypochlorite only for irrigation does not eliminate $\mathrm{Ca}(\mathrm{OH})_{2}$ competently from the root canals, though a blend of two irrigating solutions along with hand equipment enhances the elimination capacity. Thus, in this study, it was proposed to assess the efficiency of dissimilarirrigation systems

Table 1: Evaluation of mean $\mathrm{Ca}(\mathrm{OH})_{2}$ removal of three various irrigation systems at coronal, middle, and apical third

\begin{tabular}{lccccc}
\hline Irrigation systems & $\begin{array}{c}\text { Coronal } \\
(\text { Mean } \pm \text { SD) }\end{array}$ & $\begin{array}{c}\text { Middle } \\
(\text { Mean } \pm S D)\end{array}$ & $\begin{array}{c}\text { Apical } \\
\text { (Mean } \pm \text { SD) }\end{array}$ & KANOVA value & p value \\
\hline Group1: NaviTip FX irrigation & $0.89 \pm 0.13$ & $0.82 \pm 0.09$ & $1.09 \pm 0.06$ & 23.10 & 0.06 \\
Group2: Vibringe sonic irrigation & $0.52 \pm 0.07$ & $0.30 \pm 0.11$ & $0.37 \pm 0.10$ & 24.82 & $0.001^{*}$ \\
Group3: EndoVac apical negative pressure irrigation & $0.49 \pm 0.03$ & $0.32 \pm 0.16$ & $0.26 \pm 0.02$ & 24.68 & $0.001^{*}$ \\
\hline
\end{tabular}

*Highly significant

Table 2: Intergroup comparison of $\mathrm{Ca}(\mathrm{OH})_{2}$ removal at coronal third

\begin{tabular}{|c|c|c|c|}
\hline \multirow[b]{2}{*}{ Intergroup comparison } & \multicolumn{3}{|c|}{ Mann-Whitney } \\
\hline & Mean rank & $U$-test & $p$ value \\
\hline $\begin{array}{l}\text { NaviTip FX irrigation vs } \\
\text { Vibringe sonic irrigation }\end{array}$ & $24.25-5.06$ & 29.31 & $0.001^{*}$ \\
\hline $\begin{array}{l}\text { NaviTip FX irrigation vs } \\
\text { EndoVac irrigation }\end{array}$ & $22.84-7.42$ & 30.26 & $0.001^{*}$ \\
\hline $\begin{array}{l}\text { EndoVac irrigation vs } \\
\text { Vibringe sonic irrigation }\end{array}$ & $23.16-8.04$ & 32.20 & 0.782 \\
\hline
\end{tabular}

*Highly significant
Table 3: Intergroup comparison of $\mathrm{Ca}(\mathrm{OH})_{2}$ removal at middle third

\begin{tabular}{lccc}
\hline & \multicolumn{3}{c}{ Mann-Whitney } \\
Intergroup comparison & Mean rank & U-test & p value \\
\hline $\begin{array}{l}\text { NaviTip FX irrigation vs } \\
\text { Vibringe sonic irrigation }\end{array}$ & $24.50-7.16$ & 31.66 & $0.001^{*}$ \\
$\begin{array}{l}\text { NaviTip FX irrigation vs } \\
\text { EndoVac irrigation }\end{array}$ & $23.28-6.12$ & 29.40 & $0.001^{*}$ \\
$\begin{array}{l}\text { EndoVac irrigation vs } \\
\text { Vibringe sonic irrigation }\end{array}$ & $22.08-6.05$ & 28.13 & 0.972 \\
\hline${ }^{*}$ Highly significant & & & \\
\hline
\end{tabular}


Table 4: Intergroup comparison of $\mathrm{Ca}(\mathrm{OH})_{2}$ removal at apical third

\begin{tabular}{lccc}
\hline Intergroup comparison & Mean rank & U-test & p value \\
\hline $\begin{array}{l}\text { NaviTip FX irrigation vs } \\
\text { Vibringe sonic irrigation }\end{array}$ & $26.22-8.84$ & 35.06 & $0.001^{*}$ \\
$\begin{array}{l}\text { NaviTip FX irrigation vs } \\
\text { EndoVac irrigation }\end{array}$ & $25.39-7.82$ & 33.21 & $0.001^{*}$ \\
$\begin{array}{l}\text { EndoVac irrigation vs } \\
\text { Vibringe sonic irrigation }\end{array}$ & $24.48-9.14$ & 33.62 & 1.210 \\
\hline
\end{tabular}

*Highly significant

along with $\mathrm{NaOCl} /$ EDTA use for the elimination of $\mathrm{Ca}(\mathrm{OH})_{2}$ off the root canals.

In this research, the EndoVac irrigation method exhibited higher capability to take off $\mathrm{Ca}(\mathrm{OH})_{2}$ from root canals in the apical third region, pursued by Vibringe sonic irrigation and NaviTip FX irrigation techniques in that order. Likewise, Turker et al. ${ }^{13}$ found that EndoVac irrigation demonstrated significantly superior capability in eliminating $\mathrm{Ca}(\mathrm{OH})_{2}$ from the apical third region of the canals. This efficiency is due to an enhanced mechanical flush effect and vacuum aspiration phenomenon exhibited by EndoVac. Additionally, the microcannula openings aid as an exit pathway for $\mathrm{Ca}(\mathrm{OH})_{2}$ leading to its efficient elimination from the apical portion of the radicular canal. Ahmetoglu et al. ${ }^{14}$ inferred that the EndoVac irrigation proposes secure and valuable cleansing of $\mathrm{Ca}(\mathrm{OH})_{2}$ in the apical third of the radicular canal.

Yücel et al. ${ }^{15}$ came to a conclusion later that EndoVac irrigation method enhanced elimination of $\mathrm{Ca}(\mathrm{OH})_{2}$ from the coronal, middle, and apical portions leading to better cleaning of the radicular canal walls.

The highest $\mathrm{Ca}(\mathrm{OH})_{2}$ elimination capacity was exhibited by the EndoVac system of irrigation in contrast to the Vibringe sonic irrigation. Schoeffel ${ }^{16}$ have cited that in the process of sonic action, the acoustic process and cavitation consequence are absent in situations where the active tips release the irrigant and makes contact with apical gas bubble, leading to incomplete cleaning effect. Also in sonic method, less dislodgement amplitude $(1.2 \pm 0.1 \mathrm{~mm})$ of the tip employed leads to insufficient fluid motion and results in reduced cavitation referred to as the vapor lock effect, and the less energy present is not enough in the overcurrent. ${ }^{17}$ In this research, though the tip of the sonic irrigation device was positioned near the apex, low effectiveness could have resulted from the vapor lock effect that arises in the radicular canals and hampers the motion of the irrigant. Even so, the Vibringe sonic system does not have an ergonomic design and possesses a big integrated syringe organization, making it challenging for the clinician to use with shortened activation.

In this research, despite using dissimilar irrigant activation methods, total elimination of $\mathrm{Ca}(\mathrm{OH})_{2}$ could not be achieved at the apical portion of the root canal. This can be attributed to the dentinal tubular nature that is inherently few in number and irregular.

The limitations of this research are due to its design of being an in vitro study. Such in vitro studies are pioneer researches to assess the efficiency in an appropriately controlled lab atmosphere employing test replicas and in the absence of human participants. This research was performed with less sample size. Thus, further research with higher sample size is recommended.

\section{Conclusion}

Amid the limitations of this research, this research concludes that none among the irrigation methods employed could totally eliminate the $\mathrm{Ca}(\mathrm{OH})_{2}$ off the root canals. Nevertheless, EndoVac apical negative pressure irrigation has slightly superior potential in eliminating $\mathrm{Ca}(\mathrm{OH})_{2}$ from the root canals in comparison with Vibringe sonic irrigation as well as the NaviTip FX irrigation system.

\section{References}

1. Narita $\mathrm{H}$, Itoh $\mathrm{S}$, Imazato $\mathrm{S}$, et al. An explanation of the mineralization mechanism in osteoblasts induced by calcium hydroxide. Acta Biomater 2010;6(2):586-590. DOI: 10.1016/j.actbio.2009.08.005.

2. Nandini S, Velmurugan N, Kandaswamy D. Removal efficiency of calcium hydroxide intracanal medicament with two calcium chelators: volumetric analysis using spiral $\mathrm{CT}$, an in vitro study. J Endod 2006;32(11):1097-1101. DOI: 10.1016/j.joen.2006.06.005.

3. Bhuyan AC, Seal M, Pendharkar K. Effectiveness of four different techniques in removing intracanal medicament from the root canals: an in vitro study. Contemp Clin Dent 2015;6(3):309-312. DOI: 10.4103/0976-237X.161860.

4. Lambrianidis T, Kosti E, Boutsioukis C, et al. Removal efficacy of various calcium hydroxide/chlorhexidine medicaments from the root canal. Int Endod J 2006;39(1):55-61. DOI: 10.1111/j.1365-2591. 2005.01049.x.

5. Bramante CM, Pinheiro BC, Garcia RB, et al. Efficacy of the NaviTip FX irrigation needle in removing calcium hydroxide from root canal. J Clin Exp Dent 2012;4(4):e226-e229. DOI: 10.4317/jced.50857.

6. Aricioglu B, Hatipoglu O. Comparison of calcium hydroxide removal activity of new sonic system vibringe and different irrigation systems. Int J Oral Dent Health 2019;5(2):1-6. DOI: 10.23937/24695734/1510092.

7. Gupta R, Sharma H, Kumari RA, et al. Effectiveness of two techniques in removal of calcium hydroxide medicament from root canals: an in vitro assessment. J Clin Diagn Res 2018;12(7):ZC53-ZC55. DOI: 10.7860/ JCDR/2018/36025.11807.

8. Böttcher DE, Hirai VH, Da Silva Neto UX, et al. Effect of calcium hydroxide dressing on the long-term sealing ability of two different endodontic sealers: an in vitro study. Oral Surg Oral Med Oral Pathol Oral Radiol Endod 2010;110(3):386-389. DOI: 10.1016/ j.tripleo.2010.05.007.

9. Ballal $\mathrm{N}$, Kumar $\mathrm{S}$, Laxmikanth $\mathrm{H}$, et al. Comparative evaluation of different chelators in removal of calcium hydroxide preparations from root canals. Aust Dent J 2012;57(3):344-348. DOI: 10.1111/j.18347819.2012.01710.x.

10. Kuga MC, Tanomaru-Filho M, Faria G, et al. Calcium hydroxide intracanal dressing removal with different rotary instruments and irrigating solutions: ascanning electron microscopy study. Braz Dent J 2010;21(4):310-314. DOI: 10.1590/s010364402010000400004.

11. Salgado RJ, Moura-Netto C, Yamazaki AK, et al. Comparison of different irrigants on calcium hydroxide medication removal: Microscopic cleanliness evaluation. Oral Surg Oral Med Oral Pathol Oral Radiol Endod 2009;107(4):580-584. DOI: 10.1016/ j.tripleo.2008.12.008.

12. Margelos J, Eliades $G$, Verdelis $C$, et al. Interaction of calcium hydroxide with zinc oxide-eugenol type sealers: apotential clinical problem. J Endod 1997;23(1):43-48. DOI: 10.1016/S0099-2399(97)80206-3.

13. Türker SA, KoçakMM, KoçakS, etal. Comparison of calcium hydroxide removal by self-adjusting file, EndoVac, and Canal Brush agitation techniques: an in vitro study. J Conserv Dent 2013;16(5):439-443. DOI: 10.4103/0972-0707.117523.

14. Ahmetoglu F, Keles A, Simsek N. Effectiveness of the several irrigation techniques for removal of calcium hydroxide-based 
intracanal medication from an artificial standardized groove in the apical root canal. Marmara Dent J 2013;2:53-56. DOI: 10.12990/ MDJ.201317509.

15. Yücel $A C ̧$, Gürel $M, G u ̈ l e r ~ E$, et al. Comparison of final irrigation techniques in removal of calcium hydroxide. Aust Endod J. 2013;39(3):116-121. DOI: 10.1111/j.1747-4477.2011.00326.x.
16. Schoeffel GJ. The EndoVac method of endodontic irrigation, Part 3: system components and their interaction. Dent Today 2008;27(8):108-111. https://pubmed.ncbi.nlm.nih.gov/18717407/

17. Jiang $L M$, Verhaagen $B$, Versluis $M$, et al. Evaluation of a sonic device designed to activate irrigant in the root canal. J Endod 2010;36(8):143146. DOI: 10.1016/j.joen.2009.06.009. 